\title{
FILMES DE FICÇÃO CIENTÍFICA COMO MEDIADORES DE CONCEITOS RELATIVOS AO MEIO AMBIENTE
}

\section{Science fiction movies and environmental education: is it possible?}

Carlos Alberto Machado ${ }^{1}$

\begin{abstract}
Resumo: Muito se fala sobre o meio ambiente nos meios de comunicação e nas escolas, mas pouco se sabe sobre toda sua gama e envergadura. Confundem-se princípios ecológicos com o ensino generalizado do meio ambiente que cobre uma gama muito maior de conceitos e uma complexidade de relações urgentes e esquece-se que o estudo do meio ambiente deve tratar do todo envolvido pelo homem, do todo ao redor. Visões utópicas e distópicas a respeito desse tema estão presentes em alguns filmes de ficção científica feitos para cinema e televisão. Este texto analisa relações entre esses filmes e conceitos científicos relativos ao meio ambiente e aponta possibilidades de uso dos mesmos no ensino de ciência.
\end{abstract}

Palavras-chave: Ficção científica. Meio ambiente. Ensino de Ciências.

\begin{abstract}
The environment is one of the most important scientific subjects in the XXI century. Schools and the media talk about it all the time but they do not have enough knowledge. They forget that environmental studies must embrace the human beings and the whole world around them. Utopian and non-utopian conceptions about this subject are often presented in science fictions movies made for the cinema or for the television. This text discusses the relation between science fiction movies and scientific environmental concepts. In addition, it suggests a way to use the science in these kinds of films at school to develop science teaching.
\end{abstract}

Keywords: Science fiction. Environment. Science teaching.

${ }^{1}$ Doutorando em Educação pela Pontifícia Universidade Católica do Rio de Janeiro (PUC-RJ). $<$ cipexbr@yahoo.com>

Caixa Postal 24.546 - Agência Uberaba

Curitiba, PR

81.570-971 
Machado, C. A.

\section{Os debates sobre meio ambiente no Brasil}

Muito se fala sobre o meio ambiente nos meios de comunicação e nas escolas, mas pouco se sabe sobre toda sua gama e envergadura. Confundem-se princípios ecológicos com o ensino generalizado do meio ambiente, que cobre uma gama muito maior de conceitos e uma complexidade de relações urgentes. Na década de 1960, o Brasil passava por políticas ditatoriais e não demonstrava preocupações a respeito, ao contrário de outros países, sobretudo dos considerados de primeiro mundo, que vivenciavam mais intensamente os efeitos negativos de um desequilíbrio ambiental. Na década de 1970, o Brasil foi convidado a participar de um encontro internacional sobre o meio ambiente, mas foi o único a comparecer de forma diversa dos demais. Seus representantes oficiais erguiam, em plenário, faixas e cartazes com os dizeres: "Bem-vindos à poluição, estamos abertos para ela. O Brasil é um país que não tem restrições. Temos várias cidades que receberiam de braços abertos a sua poluição, porque o que nós queremos são empregos, são dólares para o nosso desenvolvimento" (DIAS, 1991, p. 4). O escândalo internacional que provocamos, autorizado pelo então ministro do interior, General Costa Cavalcanti, só evidenciou ainda mais quanto estávamos longe de ser um país ecológico ou preocupado com o meio ambiente. Encontrávamo-nos em plena adolescência política, abrindo os braços ao desenvolvimento a qualquer preço, mesmo que isso custasse o ar de nossos filhos ou de nossos descendentes. Como lembra Dias (2004), Cubatão, Rio Guaíba, Tietê, Projeto Carajás foram apenas alguns exemplos das mazelas que ainda hoje estamos tentando reparar. Na década de 1970, o Brasil confundia meio ambiente com ecologia, não entendendo que esta última estava contida no primeiro, de maior dimensão e importância.

Essa importância é corroborada nos estudos sobre a Educação Ambiental que, aos poucos, vem sendo percebida pelas políticas e seus governos. É necessário entender que a Educação Ambiental busca uma mudança nas relações de conversão, como lembra Vasconcellos (1994) em seu artigo Educação Ambiental e qualidade de vida: devemos cooperar em vez de competir, ter uma visão interdisciplinar e não individual e egoísta, saber aproveitar os recursos em vez de desperdiçá-los, e adotar o reconhecimento de direitos e deveres em vez de irresponsabilidade social. "A educação ambiental é um processo contínuo, em que não basta plantar árvores, mas inclui decidir coletivamente, não só aonde isso será feito, mas quem acompanhará o seu crescimento e as manterão saudáveis" (VASCONCELLOS, 1994, p. 16). A sociedade atual costuma incentivar, em quase tudo, a competição saudável. Sobre isso Maturana (1998) nos lembra que a competição está longe de ser sadia, porque se constitui na negação de alteridade, na negação do outro. Ele também acrescenta que "A vitória é um fenômeno cultural que se constitui na derrota do outro" (MATURANA, 1998, p. 21).

Em contrapartida, para Morin e Kern (1995) e Dias (2004), surgiram associações e partidos ecológicos; criaram-se, em setenta países, Ministérios do Meio Ambiente, Organismos Mundiais do Meio Ambiente, em detrimento da conferência de Estocolmo em 1972. A ECO-RIO conseguiu reunir 175 países que demonstraram preocupações referentes ao Meio Ambiente. Mendes e Nóbrega (2004) lembram que, hoje, sabemos que a origem do conhecimento depende da existência do mundo, que, por sua vez, é inseparável de nosso corpo, de nossa linguagem e de nossa história social. Assim sendo, o estudo do meio ambiente deve tratar do todo envolvido pelo homem, do todo ao redor (MATURANA, 1998).

Uma visão consciente a respeito desse tema é evidenciada no filme de ficção científi- 
ca (FC) dirigido por Douglas Trumbull: A Corrida Silenciosa - Silent Running, USA (1972). Nele, o botânico Freeman Lowell (Bruce Dern) há três anos preservava, em nove enormes domos geodésicos flutuando em órbita de Júpiter, os únicos espécimes botânicos que restaram da Terra, transformada em concreto puro. Consciente da situação que estava em suas mãos, rebela-se contra seus dois companheiros, após receber a ordem da Terra de que deveriam destruir as espécies restantes e voltar para casa. Fugindo em desespero para os anéis de Saturno com uma única nave restante, e tendo a esperança de que, um dia, a humanidade se arrependeria de seu ato insano, Freeman deixa programados dois robôs para que cuidem da floresta restante, possivelmente o único vestígio verde do sistema solar, quiçá da galáxia.

Já em 1972, Douglas Trumbull sensibilizou-se com o presente investindo em um filme que, no mínimo, tocou uma platéia desavisada sobre uma catástrofe eminente que ela mesma estaria providenciando aos poucos. Estamos em 2007 e essa visão apocalíptica de Trumbull ainda é uma possibilidade assustadora. Em pesquisa realizada durante o curso de mestrado (MACHADO, 2000), evidencio que esse filme vem sendo utilizado em sala de aula por vários professores de biologia e ciências, como um demonstrativo de quão importante é a preservação do meio ambiente. Segundo Murray (2003), a importância da narrativa que está presente na FC é reforçada como mecanismo cognitivo primário para a compreensão do mundo.

Essa consciência, que vem sendo buscada desde que o homem percebeu seu papel na natureza e o que vinha fazendo dela, é objeto de reflexão por parte de inúmeros pensadores. Pesquisadores que estão refletindo e percebendo que, mesmo com os projetos e gestões atuais, ainda estamos longe de alcançar o ideal. Como afirma Dias (2004), involuimos ética e espiritualmente. A necessidade de novos paradigmas para se tentar resolver os problemas que são muitos e multiplicadores, urge. Pensadores como Morin e Prigogine tentam, a sua maneira, sugerir caminhos que podemos seguir. Os modelos insustentáveis vigentes nos obrigam a tentar encontrar modelos auto-sustentáveis, mas que exigem sacrifícios de todos. Sacrifícios esses compreendidos, mas não respeitáveis. Morin e Kern (1995, p. 11) acrescentam que: "Homens de saber alheios à dialógica da complexidade não passam de gafanhotos - simpáticos, quando isolados; predadores, em bando." A indústria continua a fabricar objetos de consumo em grande escala e muita poluição. Concebem filtros que, quando funcionam, apenas amenizam a situação. Meros paliativos. $O$ futuro sem sustentação não garante mais nada. Não existem previsões seguras. Acrescentando-se a isso, ainda agrava-se a crise ambiental, provocando mudanças indesejáveis.

Filmes distópicos de FC recentes, como Waterworld - o segredo das águas, USA (1995), de Kevin Reynolds, e O Mensageiro - The Postman, USA (1997), de Kevin Costner, ambos estrelados por esse último, evidenciam mundos pós-apocalípticos onde é difícil sobreviver. $\mathrm{O}$ primeiro passa-se após o degelo, conseqüência do calor extremo provocado pelo aumento do "buraco" ocasionado pela poluição na camada de ozônio, que a humanidade não conseguiu reverter. Apesar da água 'salgada' abundante, água 'potável' e terra equivaliam aos metais preciosos de nossa era. A conscientização de que o homem precisa tomar providencias fica evidente nessa película, mal recebida pela crítica cinematográfica. O segundo filme, não menos importante, passa-se após a $3^{\text {a }}$ Guerra Mundial. Poucos grupos de homens sobreviveram, e os que restaram não conseguem se comunicar. A mata Atlântica sobrevive e acaba servindo de obstáculo para as poucas aldeias existentes, onde residem grupos de assaltantes. O protagonista vivenciado por Costner acaba tendo um insight em meio a essa correria e reinventa o 
Machado, C. A.

correio, utilizando, para isso, ele próprio e um cavalo. Procura atravessar os campos e matas levando cartas de uma aldeia a outra, tentando incentivar o retorno da comunicação entre os seus. Com o tempo a idéia contagia e várias pessoas acabam ingressando na nova missão, pois descobrem que a comunicação é um importante atributo para a sobrevivência da humanidade, mesmo em um mundo aparentemente sem esperanças.

Vivemos de projeções quanto ao devir que provocam angústias em relação ao nosso futuro e ao de nossos descendentes. É preciso "pensar o futuro sem abandonar o presente" (MORIN e KERN, 1995, p. 12). Este artigo pretende mostrar que a FC, com a multiplicidade de visões futuras que a caracteriza, pode auxiliar o educador a desenvolver criticamente, com seus alunos, assuntos de meio ambiente tão necessários em nossos dias, pois, gostemos ou não, ainda estamos na idade de ferro planetária (MORIN e KERN, 1995).

\section{Filmes de ficção científica como mediadores de conceitos relativos ao meio ambiente}

$\mathrm{Na}$ contemporaneidade, a FC é o gênero de filmes mais procurado pelos adolescentes e pela população em geral. Basta checarmos as pesquisas de mercado. Essa busca é resultado, por um lado, da avançada tecnologia que Hollywood vem empregando cada vez mais em seus produtos cinematográficos e televisivos e, por outro, da intensa fascinação que narrativas sobre o futuro exercem, especialmente, sobre os jovens. São os filmes de FC que costumam ter mais sucesso de bilheteria ou uma audiência maior, e são também os mais comentados pela mídia, devido, em grande parte, aos efeitos especiais.

Alguns pensadores acreditam que a vida, em seu contexto mais elevado, possivelmente seja uma característica particular e privilegiada de nosso planeta. Por outro lado, outros, como Morin, pensam que ela pulula pelo cosmos. De qualquer forma, isso não a desmerece em absoluto, pelo contrário, deve ser preservada e respeitada. "Existe a elevadíssima probabilidade de que, num universo de bilhões e bilhões de astros, haja milhões de planetas análogos a Terra, portanto, a probabilidade de existência de seres vivos em outras regiões do cosmos" (MORIN e KERN, 1995, p. 53). O planeta não é nosso, mas sim nossa moradia. Não somos proprietários, apenas locatários e, como tal, devemos cuidar de nosso "quintal", pois é apenas esse que temos. Não se pode mais separar homem, natureza, vida, cosmos. Terra, um pequeno cesto de lixo cósmico, transformado em nosso jardim e, assim sendo, rara, frágil e preciosa. Viver fora da biosfera é praticamente impossível. Se um dia formos para o espaço, como pareçe ser inevitável devido ao crescimento populacional desenfreado da humanidade, teremos de dar um jeito de levar junto conosco o ar que respiramos, o verde que fabrica o ar e o alimento que nos sustenta. "Nenhum ser vivo, mesmo humano pode libertar-se da biosfera" (MORIN e KERN, 1995, p. 55). Essa afirmação é muito bem trabalhada, mostrando os dois lados da moeda, no filme já citado A Corrida Silenciosa - Silent Running (1972).

Morin e Kern (1995) também advertem que não conhecemos todo tipo de vida que possa existir no universo, e que pode, inclusive, neste momento, haver alguma forma de vida desconhecida ao nosso redor: 
Filmes de ficção científica como mediadores...

não se pode descartar uma terceira hipótese; talvez haja no universo, organizações muito complexas, dotadas de propriedades, de autonomia, de inteligência e até de pensamento, mas que não estariam fundadas numa organização núcleo-protéica e que seriam (atualmente? para sempre?) inacessíveis à nossa percepção e a nosso entendimento. (MORIN e KERN, 1995, p. 54)

Ora, a FC formulou essa hipótese há muito tempo: a idéia de que pode haver seres vivos completamente diferentes do ser humano, baseados em silício, hidrogênio e até em elementos desconhecidos para nossa ciência. As séries Jornada nas Estrelas (1966-2001), Babylon 5 (1994-1998), de J. Michael Straczynski, Stargate - SG1, CAN/USA (1997), de Mario Azzopardi e Dennis Berry, e Stargate - Atlantis, CAN/USA (2004), de Brad Wrighte Robert Cooper, são quatro bons exemplos que ilustram essas hipóteses. Elas falam da possibilidade de virmos a conviver, em um futuro relativamente próximo, com espécies biológica e culturalmente muito distintas de nós.

Segundo Morin e Kern (1995), a superação de nossas cegueiras ego-etnocêntricas ou ideológicas só desaparecerá quando alcançarmos o desenvolvimento correlato da compaixão do coração, do humanismo de espírito, do verdadeiro universalismo e, sobretudo, do respeito às diferenças. O preconceito e o racismo ainda prevalecem no ser humano. Homem bicho/bicho homem, a noção de homem se desfez em fragmentos e o estruturalismo pensou poder eliminar esse "fantasma irrisório".

O episódio Os Filhos de Platão - Plato's Stepchildren (1968), de David Alexander, da série clássica de Jornada nas Estrelas exibida, há mais de quarenta anos, mostra o primeiro beijo interracial da história da televisão. A série não só propugnava a convivência entre diferentes, em plena década de 1960, como fazia questão de mostrar que a tripulação da Enterprise era composta de representantes de países terrestres que, naquele momento (Guerra Fria), estavam em conflito. Além dos norte-americanos e, naturalmente de alienígenas como o vulcano Sr. Spock, existiam tripulantes de diferentes países e continentes da Terra, como Japão, Rússia, Escócia e África.

Atualmente, está em evidência falar e escrever sobre "desenvolvimento sustentável", mas cria-se um dilema, um contraponto, pois "põe em dialógica a idéia de desenvolvimento, que comporta aumento das poluições, e a idéia de meio ambiente, que requer limitação das poluições” (MORIN e KERN, 1995, p. 74). Buscar um desenvolvimento sem poluição seria uma alternativa lógica que já vem sendo pesquisada em vários países, inclusive no Brasil. $\mathrm{O}$ engenheiro curitibano Emilio Hoffmann Neto publicou, em 2005, seu livro Hidrogênio: evoluir sem poluir, que aponta várias maneiras de utilizarmos o hidrogênio como forma alternativa para soluções de problemas ambientais. $\mathrm{Na}$ introdução de sua obra, ele lança mão de um conto de FC para descrever como seria, em sua imaginação, nosso planeta com o uso desse elemento químico. Seria uma utopia social?

Enquanto a utopia de Platão nos leva a imaginar apenas um tipo de sociedade, o pluralismo encontrado na FC, devido à enorme quantidade de livros e filmes do gênero, nos permite pensar em múltiplas possibilidades e nos proporciona visões mais plurais e pormenorizadas de futuros possíveis. Apesar de ser constantemente associada ao futuro, a FC é, acima de tudo, uma análise do presente. Um bom exemplo disso vem de 1969, quando Solaris 
foi exibido nas telas de cinema, pela maestria do diretor soviético Andrei Tarkovsky. Bressand e Distler (1989) recordam que o cineasta, desprezando o habitual cenário eletrônico, apresenta, em Solaris, um futuro pleno de nostalgia, que nos conduz à contemporaneidade. Por meio do protagnista, o filme sempre expõe o telespectador a situações e problemas do cotidiano, situações que, muitas vezes, podem gerar conflitos e angústias, como: a relação entre pais e filhos, problemas entre casais, imaturidades sexuais e até aberrações contidas. Tudo isso é visto no filme por meio dos desejos inconscientes materializados pelo planeta Solaris, na verdade uma entidade viva, que, ao contrário do que possa parecer para alguns, só queria realizar um tipo de contato, o seu tipo de contato. "O oceano de Solaris é bem, portanto, o símbolo simultaneamente de uma perdição possível e de uma superação imaginável.” (BRESSAND e DISTLER, 1989, p. 35).

A evolução tecnológica dicotomicamente diferente da do homem acaba por trazer preocupações com o futuro. Esse tema também está presente na FC distópica, como se vê em Passageiro do Futuro - LawnmowerMan (1992), de Brett Leonard, onde a tecnologia representa diversão e, ao mesmo tempo, ditadura. Um deficiente mental é requisitado para uma experiência "não oficial" em um projeto de desenvolvimento mental, proporcionado por intermédio de jogos virtuais para computador. O experimento não apenas dá certo como se sobrepuja ao lançar a mente do protagonista para as linhas telefônicas e para a Internet. De dominado para dominador.

Mas não é apenas neste texto fílmico que observamos essa realidade. Em nossos dias, foi lançada, pelos japoneses, mais precisamente em outubro de 1981, uma expedição para "a criação do computador que converse em linguagem natural com seu utilizador e que seja capaz de efetuar deduções e de dirigir o seu próprio processo de aprendizagem, coisas que até agora se consideravam apanágio do homem" (BRESSAND e DISTLER, 1989, p. 51). Ora, se o homem ainda não se entende, quem dirá com as máquinas que estão surgindo. A premissa de que o Fantasma da Máquina está presente, cada vez está mais próxima. E é exatamente disso que trata o filme Matrix, (1999) dos irmãos Andy e Larry Wachowski, onde o homem se transformou em um tipo de pilha ou bateria para alimentação de máquinas dominadoras que, em troca, proporcionam ao homem uma "liberdade" virtual, uma fantasia de vida real. Em paralelo à nossa realidade, atualmente, existem jogos virtuais denominados Second Life, que estão, aos poucos, virando febre ao redor do mundo.

Segundo Morin e Kern (1995), após a Segunda Grande Guerra, surgiram grandes esperanças progressistas. Um futuro utópico era aguardado pela população. O futuro radioso naufragou na carona da revolução socialista, no sistema totalitário na Rússia e nas guerras da Coréia e do Vietnã.

Nesse período, a FC de George Orwel 1984, escrito em 1948, e Admirável Mundo Novo (1931), de Aldoux Huxley, parecem explicitar o sentimento de que o sonho acabou. O futuro seria negativo e aterrador. A ciência tornaria os governos totalitários e dominadores, uma população engendrada geneticamente seria subserviente e melancólica. Sem dúvida, esses contos eram um alerta para a humanidade do que poderia estar por vir se nada fosse feito para mudar o curso da história.

As solidariedades locais, que funcionavam muito bem, estão, gradativamente, desaparecendo entre as sociedades. Os políticos não conseguem incorporar, em seus programas, os problemas da civilização que se tornam políticos. O que se vê são paliativos ou remediações na 
tentativa de se resolverem as dificuldades sociais locais. Partidos e candidatos prometem, e até cumprem parcialmente, a realização de projetos sociais destinados a solucionar problemas como fome, moradia, desemprego, mas apaziguam a situação apenas momentaneamente. Não atingem a raiz do problema. "A racionalidade fechada produz irracionalidade", dizem Morin e Kern (1995, p. 95). O desvio do rio São Francisco, persistido pelo governo atual, é um exemplo do que explanamos aqui. Os seres humanos continuam insistindo em querer dominar a natureza, esquecendo-se de que fazem parte dela: "O homem transformou a Terra, domesticou suas superfícies, vegetais, tornou-se senhor de seus animais. Mas não é o senhor do mundo, nem mesmo da Terra" (p. 185). Seus poderes técnicos, seu pensamento, sua consciência devem, doravante, ser destinados, não a dominar, mas a arrumar, melhorar, compreender.

Em concomitância com esse pensador, encontramos pensamentos semelhantes na obra de Maturana e algumas sugestões alternativas:

Uma educação que nos leve a atuar na conservação da natureza, a entendê-la, para viver com ela e nela, sem pretender dominá-la, uma educação que nos permita viver na responsabilidade individual e social, que afaste o abuso e traga consigo a colaboração na criação de um projeto nacional em que o abuso e a pobreza sejam erros que se possam e se queiram corrigir. (MATURANA, 1998, p. 35)

A tecnologia atual poderia resolver, verdadeiramente, problemas como erradicação da fome e desenvolver uma educação para a complexidade, mas isso ainda não se verificou. Recorro novamente à série Jornada nas Estrelas-Nova Geração (1987) que, no episódio A Zona Neutra - The Neutral Zone, de James Conway, evidencia uma sociedade livre de preceitos capitalistas, onde não existe mais a posse material e o dinheiro. Todos trabalham solidariamente para melhorar a sociedade, não lhes faltando moradia ou comida. A exploração do conhecimento é a filosofia do bomo-futurus, seria uma utopia inalcançável?

Morin e Kern (1995) acreditam que existe uma extrema variedade de possíveis roteiros futuros; não existe apenas um ou alguns poucos caminhos como se acreditava antes. Isso é perfeitamente demonstrado na série Sliders (1995), cujos protagonistas viajam, a cada episódio, para Terras paralelas onde existem infinitas possibilidades de vida em um mesmo período de tempo. "Histórias multiformes podem ajudar-nos a perceber causas complexas de acontecimentos complexos, assim como imaginar diferentes desfechos para uma mesma situação" (MURRAY, 2003, p. 10).

A série Sliders, em vários episódios, bem como muitas outras séries de FC, demonstram como os hábitos são difíceis de se modificarem. Alertando para isso, Maturana (1998) lembra que, quando ingressamos uma criança em um colégio, as interações com o ambiente em que ela está é que irão formar seus hábitos. Portanto, de acordo com a escolha dos pais, o professor e o educador têm uma enorme responsabilidade em suas mãos: estão influenciando a educação e o futuro de várias gerações, estão atuando como moldadores do futuro. Nesse contexto, trabalhar com diferentes pontos de vista futuros pode ampliar reflexões sobre o presente. 
Machado, C. A.

\section{Existem soluções?}

De acordo com Morin e Kern (1995), o tempo alterou-se devido à tecnologia civilizatória e, dessa forma, necessitamos literalmente desacelerar a marcha para chegarmos a um outro futuro.

O consumo vira histeria para os ricos. Procuram a bibelomania pensando apenas no aqui e agora; o turismo não procura relações pessoais, mas apenas folclores e monumentos. Morin e Kern (1995, p. 92) alerta ainda para a seguinte questão: "Nossa civilização marcha para sua autodestruição ou sua metamorfose?"

Ele aposta na metamorfose, pois acredita que a esperança e a solução para os problemas da humanidade residem no verdadeiro amor. Maturana (1998) concorda com Morin a esse respeito. Ambos acreditam que o Amor seja a resposta primordial que mobiliza a solidariedade. Mas Maturana acrescenta: "prega-se o amor, mas ninguém sabe em que ele consiste porque não se vêem as ações que o constituem, e se olha para ele como a expressão de um sentir. Ensina-se a desejar a justiça, mas os adultos vivem na falsidade" (MATURANA, 1998, p. 36). Contradições à parte, o homem, sem dúvida, ainda tem muito que aprender. O problema é que nossa tecnologia está evoluindo muito rápido e nós estamos apenas engatinhando na condição de compreendê-la e poder usá-la de forma inteligente. A desigualdade dessa evolução é tão evidente que tememos por nós mesmos. É como uma criança no berço com uma arma na mão. O perigo espreita constantemente.

Em contrapartida, música, cinema, danças, jogos e brinquedos atravessam fronteiras levando a memória de quem os criou além de sua própria morte (MENDES e NÓBREGA, 2004). É a verdadeira imortalidade por meio de seus feitos, e não por intermédio de sua ganância, como nos lembra Arendt (2004). Além disso, a autora de Condição Humana também afirma o que a biologia atualmente nos demonstra, que temos "tudo" dentro de nós. Essa afirmação é reforçada pelo filósofo Konder (2005, p. 42), parafraseando os Ensaios de Montaigne: "cada indivíduo traz com ele, inteira, a condição humana".

O Homo occidentalis de Morin, até a metade do século passado, era ignorante de que trazia toda a história do cosmo (identidade terrestre e cósmica) dentro de si. O filme Viagens Alucinantes - Altered States, USA (1980), de Ken Russell, demonstra didaticamente muito bem esse conceito quando o protagonista, após ter sido cobaia de sua própria experiência, viaja, literalmente, para dentro de sua mente, para o princípio da história da humanidade e da criação, quase que se obscurecendo totalmente. O cientista do filme, como muitos em nossa realidade, insistia em analisar a origem do homem apenas pela razão e pela práxis. Finalmente, percebeu que as emoções - no caso, o amor - eram o que o salvaria.

Para Maturana "as emoções dominam a razão. Todo sistema racional se constitui no operar com premissas aceitas, a partir de uma certa emoção. [...] Conhecer as emoções do outro permite conhecer suas ações" (MATURANA, 1998, p. 16, 23). A série Jornada nas Estrelas-Nova Geração, por meio de seu personagem Data, expressa muito bem essa idéia da emoção por trás da razão. Data é um andróide sofisticado, análogo fisicamente ao ser humano, que é movido integralmente pela razão, mas busca, constantemente, compreender os sentimentos humanos a ponto de receber um chip de emoções, pois só assim, no caso dele, isso seria possível. A busca frenética e utópica de Data por emoções humanas nos faz ponderar quanto os sentimentos são importantes em nossas ações e na tomada de decisões. Antes de 
Filmes de ficção científica como mediadores...

receber o $c h i p$, muitas vezes, Data realiza algumas funções sem compreender o porquê de estar fazendo aquilo, precisamente por lhe faltarem emoções. O fato de Data não entender o sentido das emoções e, dessa forma, não conseguir reproduzi-las como os humanos as compreendem (como as artes, por exemplo), nos alerta, como recorda Maturana (1998), para quão elas são importantes em nossas ações e, conseqüentemente, em nossas vidas.

\section{Planeta sob controle}

O homem é guiado pela idéia de controle, o que acarreta a exclusão do outro. Além disso, como adverte Maturana (1998, p. 55), "estamos imersos na idéia de que temos que controlar a natureza, porque cremos que o conhecimento permite o controle". Na FC vemos, constantemente, essa crença sendo contestada. Os filmes que melhor exemplificam essa contestação são: Impacto Profundo - Deep Impact, USA (1998), de Mimi Leder, onde o 'impacto' não é apenas na natureza, mas no ego humano, que pensa ser dono e proprietário da natureza. Impotente perante uma ameaça de um asteróide gigantesco, um grupo seleto de pessoas é obrigado a esconder-se nas profundezas da Terra, deixando, em sua hipocrisia, a maioria dos seres humanos do lado de fora, sob a alegação de que a humanidade precisava sobreviver. $O$ Dia depois de Amanbã - The Day After Tomorrow, USA (2004), de Roland Emmerich, é outro filme exemplar em demonstrar a arrogância do homem perante as forças da natureza. Um climatologista tenta alertar os governantes do planeta de que a Terra poderia estar prestes a extinguir-se como a conhecemos, em uma Nova Era Glacial, em conseqüência do derretimento da calota polar, por causa do buraco de ozônio, mas é ignorado. Tornados arrasam Los Angeles; um maremoto submerge Nova York, e todo o hemisfério norte começa a congelar. O inimigo, neste caso, é imbatível, a própria natureza! Já o acolhimento dos sobreviventes do hemisfério norte pela população do hemisfério sul é um interessante exemplo de alteridade e solidariedade que emergem como contrapartida a um futuro trágico.

A aceitação do outro é relevante, pois "se não tenho imaginação para incorporar aqueles japoneses [vítimas de Hiroshima e Nagazaki] no meu mundo, aceitando-os como legítimos outros na convivência, não posso preocupar-me com o que lhes acontece como conseqüência de meus atos" (MATURANA, 1998, p. 73).

\section{Usando filmes de FC na escola}

Usar trechos específicos dos filmes mencionados nesse texto, bem como de outros, que podem ser pesquisados pelo professor, seria o mais recomendado. Um trecho do início da obra cinematográfica Blade Runner, por exemplo, pode permitir ao educador explanar sobre nuvens, chuva ácida e poluição. Também podem ser explorados o conceito de superpopulação e a inexistência de animais domésticos num futuro relativamente próximo. Narrativas fílmicas exercem uma forte atração sobre crianças e adolescentes, e a presença delas em contextos de ensino pode contribuir para despertar o interesse por temáticas complexas e de difícil compreensão. Para uma edição "doméstica", o professor interessado pode realizar sua fita matriz utilizando dois aparelhos de videocassete, ou, se for o caso, um computador po- 
tente que contenha placa de captura de vídeo e um gravador de DVD. Como nem todos têm acesso ao conhecimento da edição de imagens, recomenda-se a procura de profissionais da área e/ou produtoras de vídeo. O custo-benefício acaba compensando, visto que as fitas (ou DVDs) editadas poderão ser reutilizadas em várias aulas. A maneira como serão utilizadas as imagens e a forma como o professor ministrará sua aula poderão constantemente ser modificadas de acordo com seu programa, seus objetivos e o tema em debate.

Os exemplos a seguir servem para demonstrar, ao professor, como é possível cruzar conteúdos disciplinares com conteúdos cinematográficos, advindos de filmes de FC.

O filme Corrida Silenciosa (1972), de Douglas Trumbull, explana a falta total de vegetação e vida animal silvestre no futuro da Terra. As últimas florestas, bem como seus habitantes, pertencem a nove domos, que estão inseridos em três gigantescas naves em órbita de Júpiter. Cada nave é zelada apenas por um cientista. Um deles, um tipo de astronauta botânico, Freeman Lowell, vivenciado pelo ator Bruce Dern, é o único que valoriza, acima de tudo, a vida em todos os seus sentidos, preservada dentro daquelas encubadoras espaciais. Devido à dependência tecnológica desenfreada, os astronautas recebem ordem de destruir as florestas, pois as pessoas da Terra já não lembram mais o que são árvores e vida animal e, portanto, acreditam não necessitar mais disso. O ecologista radical perde o controle ao ver os domos sendo explodidos e transforma-se em um assassino fundamentalista ao matar seus colegas para preservar a destruição da última esperança vegetal.

O filme choca os mais desavisados, pois não se espera uma reação tão contundente de um ativista ecológico, mas serve para demonstrar, e discutir, entre outras coisas, a importância da preservação ambiental e de seu desenvolvimento sustentável. Dessa forma, o professor pode levantar questionamentos como: - Partindo do que sabemos hoje sobre desmatamentos, poluição e educação ambiental, nossa sociedade pode estar partindo para essa direção? - O que podemos fazer para diminuir e colaborar com o desenvolvimento sustentável?

Também podem ser levantadas questões norteadoras relativas à filosofia dentro do conteúdo sobre desenvolvimento sustentável, como: - Existe alguma diferença entre o que foi visto, no filme, sobre o esquecimento, por parte da humanidade, da existência da natureza nesse caso, de árvores e animais - e a extinção de algumas espécies de animais nos dias atuais?

- O fato de não conhecermos um canguru australiano nos isenta de responsabilidades com relação à sobrevivência de sua espécie?

Outro filme digno de nota é Contato (1997), do diretor Robert Zemeckis, baseado em livro homônimo de Carl Sagan. Nele, uma cientista ortodoxa procura insistentemente por vida fora do planeta. Ao encontrar vida, convence o governo a fabricar um aparelho que a transportará aos confins do espaço onde manterá contato com tal civilização extraterrena.

Já no início do filme, temos uma imagem que fala por si. A imagem afasta-se aos poucos evidenciando parte de nosso Sistema Solar, e, à medida que o faz, ouvem-se, ao fundo, sons emitidos de programas de rádios de vários períodos de tempo. Quanto mais a imagem fica distante no espaço - planetas, nebulosas, galáxias -, mais os sons escutados retornam no tempo, até que a imagem afasta-se mais e mais para as profundezas do Universo.

Apenas esse trecho do filme pode ser utilizado para descrever o tamanho e posição aproximados de nosso sistema solar, de nossa galáxia e do universo. Aqui temos um exemplo de como trabalhar com o tema meio ambiente de forma transversal, pois se pode discutir, com o aluno, sobre: distâncias de planetas e estrelas, a probabilidade de vida fora da Terra, a impossibilidade de propagação do som no espaço, a velocidade do som e da luz, entre outras 
Filmes de ficção científica como mediadores...

coisas. E todas essas informações apenas em uma cena de três minutos: - Se uma viagem para a Lua, nosso satélite natural, partindo da Terra, leva três dias, quantos dias levariam para atravessar o Sistema Solar, ou para ir de um planeta a outro de nosso sistema? - Qual a diferença do Sistema Solar demonstrado no filme e do Sistema Solar de seu livro escolar?

Aqui também é possível a seguinte reflexão: - Percebendo a imensidão do Universo (ou do Cosmos), você acredita que estamos sozinhos?

Sem contar que todo filme de FC auxilia na reflexão sistemática do processo de produção e distribuição dos bens culturais, que são constantemente demonstrados de forma especulativa. Isso poderá ocasionar a cultura científica tão almejada e necessária em nosso dias, pois esses filmes auxiliam na busca de implicações éticas e ambientais.

\section{Roteiro para os filmes VHS ou DVD}

Inicialmente, o professor deve assistir aos filmes a serem editados, ou seja, os filmes de FC citados, ou os de sua preferência, que pretende utilizar como exemplos de seus conteúdos. Portanto, irá, literalmente, cortar alguns pedaços que têm a ver com o(s) conteúdo(s) da(s) disciplina(s). Um roteiro simples deve ser elaborado, como um pequeno plano de aula. Para isso, separam-se os trechos específicos, anotando-se a seqüência em uma folha branca ou uma ficha previamente elaborada. Pode-se colocar o tempo de início da imagem e o tempo de término, para facilitar a edição. O tempo pode ser cronometrado pelo início do filme ou, preferencialmente, pelo counter do aparelho de vídeo ou DVD. Verificar a seqüência das imagens de acordo com a seqüência do conteúdo específico da matéria. Para facilitar, coloca-se a descrição das imagens do lado direito da folha, com os respectivos tempos, e, do lado esquerdo, insere-se o trecho do conteúdo da matéria. Exemplo:

\begin{tabular}{|c|c|c|}
\hline Matéria (Genética-Biologia) & Tempo (duração) & Filme (Gattaca) \\
\hline DNA & De 0:04'00" a 0:04'45" & $\begin{array}{c}\text { Cena do dedo do protagonista no painel de } \\
\text { identificação de DNA, no ambiente de trabalho, } \\
\text { para confirmar sua identidade }\end{array}$ \\
\hline
\end{tabular}

OBS: Esse procedimento serve para facilitar o trabalho do professor, ou do editor de uma produtora, que poderá editá-lo.

Os episódios de seriados de tevê não necessitam de edição, pois costumam ser mais curtos, em comparação ao filmes feitos para cinema, tendo, em geral, de 45 a 50 minutos de duração. Eles também seriam uma forma adequada para se discutirem conceitos relativos a conteúdos específicos sobre o meio ambiente. Alguns exemplos de episódios de várias séries foram citados neste artigo e muitos outros podem ser encontrados e pesquisados pelo professor interessado. Muitas dessas séries estão entrando no mercado brasileiro e basta ficarmos alertas para seus lançamentos.

Vale lembrar que filmes não são meros instrumentos didáticos. Eles têm uma história, uma forma de produção e diferenças estéticas e narrativas que precisam ser mencionadas quando da exibição deles em contextos de ensino. Filmes de ficção científica têm uma magia e 
Machado, C. A.

um encanto muito próprios, são calcados na fantasia e estimulam a imaginação e a criatividade. Não devem, portanto, ser tomados exclusivamente como recurso para se trabalhar um certo conteúdo curricular. O cinema é uma forma de arte e deve ser visto e apresentado como tal.

\section{Referências}

BRESSAND, A.; DISTLER, C. O mundo de amanhã. Lisboa: Dom Quixote, 1989. (Coleção Universidade Moderna, n. 85).

DIAS, G. F. Educação ambiental: princípios e práticas. 9. ed. São Paulo: Gaia, 2004.

. Os 15 anos da educação ambiental no Brasil: um depoimento. Revista Em Aberto, Brasília, v. 10, n. 49, p. 3-14, 1991.

HARENDT, H. A condição humana. 10. ed. Rio de Janeiro: Forense, 2004.

KONDER, L. As artes da palavra. São Paulo: Boitempo, 2005.

MACHADO, C. A. Contribuições da ficção científica para o conhecimento e a aprendizagem. 2000. 140 f. Dissertação (Mestrado em Educação) - Setor de Ciências Humanas, Letras e Artes, Universidade Federal do Paraná, Curitiba, 2000.

MATURANA, H. Emoções e linguagem na educação e na política. Belo Horizonte: Editora UFMG, 1998.

MENDES, M. I. B. S.; NÓBREGA, T. P. Corpo, natureza e cultura: contribuições para a educação. Revista Brasileira de Educação, n. 27, p. 125-137, p. 125-137, 2004.

MORIN, E.; KERN, A. B. Terra-Pátria. Porto Alegre: Sulina, 1995.

MURRAY, J. H. Hamlet no Holodeck: o futuro da narrativa no ciberespaço. São Paulo: Itaú Cultural/Unesp, 2003.

NETO, E. H. G. Hidrogênio: evoluir sem poluir. Curitiba: Brasil H2 Fuel Cell Energy, 2005.

VASCONCELLOS, H. S. Educação ambiental e qualidade de vida. Revista Nova América, n. 61, p. 14-16, 1994.

\section{Referências cinematográficas}

IMDB. Disponível em: <http://www.imdb.com/>. Acesso em: 30 jun. 2005.

Artigo recebido em maio de 2007 e aprovado em junho de 2007. 